\title{
IMIGRAÇÃO E DESAMPARO NOS FILHOS DE DEKASSEGUIS
}

Immigration and helplessness in dekassegui children

\author{
Mary Yoko Okamoto* \\ José Sterza Justo** \\ Cizina Célia Fernandes Pereira Resstel ${ }^{* * *}$
}

\begin{abstract}
Resumo. O fenômeno do retorno dos dekasseguis - fluxo migratório de descendentes de japoneses ao Japão - ganhou visibilidade no Brasil, principalmente a partir da crise econômica mundial de 2008, quando aumentaram os retornos dos brasileiros. O objetivo da pesquisa foi investigar a experiência migratória dos filhos de dekasseguis que acompanharam seus pais no retorno ao Brasil. Para tanto, apresentamos um estudo de caso com uma menina de treze anos, nascida no Japão e que havia chegado recentemente ao Brasil com seus pais. Os resultados indicam que a infância vivida no Japão produz identificações profundas com a cultura japonesa. Algumas sequer falam o português, se consideram japonesas e se sentem estrangeiras no Brasil. As sensações de estranhamento e o desamparo predominam na experiência desses filhos de dekasseguis.
\end{abstract}

Palavras-chave: Dekasseguis, imigração, retorno, desamparo.

\begin{abstract}
The phenomenon of the return of dekasseguis - migratory flow of Japaneses descendants to Japan - gained visibility in Brazil mainly after the global economic crisis of 2008, when the returns of Brazilians increased. The objective of this research was to investigate the migratory experience of these children of dekasseguis that accompanied his parents on their return to Brazil. Thus, we present a case study with a girl of thirteen, born in Japan and had recently arrived to Brazil with her parents. The results indicate that the childhood experienced in Japan produced deep identifications with Japanese culture; some go as far as not speaking Portuguese, considering themselves Japanese and founding themselves foreigners in Brazil. Feelings of estrangement and helplessness prevail in the experience of these dekassegui children.
\end{abstract}

Keywords: Dekasseguis, immigration, return, helplessness.

* Faculdade de Ciências e Letras de Assis - Universidade Estadual Paulista "Júlio de Mequita Filho" - UNESP. São Paulo, SP, Brasil.

** Programa de Pós-graduação em Psicologia da Faculdade de Ciências e Letras de Assis Universidade Estadual Paulista "Julio de Mesquita Filho" - UNESP. São Paulo, SP, Brasil.

*** Doutoranda na Faculdade de Ciências e Letras de Assis - Universidade Estadual Paulista "Júlio de Mesquita Filho" - UNESP. São Paulo, SP, Brasil. 


\section{O movimento dekassegui ${ }^{1}$}

Nas décadas de 1980 e 1990 houve um aumento significativo no fluxo de brasileiros descendentes de japoneses que passaram a se deslocar para o Japão, em busca de trabalho, fenômeno conhecido como dekassegui. Tal fluxo ${ }^{2}$ se somou a tantos outros, com desdobramentos importantes nos planos econômico, político, das relações familiares, da produção de subjetividade, dentre muitos que se poderia mencionar.

O caso dos dekasseguis é exemplar como experiência radical de encontro/ confronto com o estrangeiro, com o "Outro". Apesar de descendentes de japoneses, quando emigram para a terra de seus antepassados percebem-se brasileiros e não japoneses. Talvez como nenhum outro fluxo migratório, este embute, de maneira muito forte, a perspectiva do retorno e da convivência com realidades nacionais distantes e distintas. Por um lado, continuam sendo afetados por acontecimentos que ocorrem no Brasil e, por outro, vivem aqueles que ocorrem no Japão. Num certo sentido, vivem um espaço que se cria "entre" um país e outro, uma cultura e outra, entre ambas nacionalidades. O transnacionalismo ${ }^{3}$ é praticado com bastante intensidade e contundência pelos dekasseguis, isto é, eles são capazes de habitarem simultaneamente os dois países, mantendo contato constante, com familiares e outras pessoas de seus círculos de relacionamentos, residentes no Brasil. Não apenas mantém contatos, como também disparam à distancia ações de todo tipo que afetam as pessoas com as quais se relacionam e repercutem na localidade e até no cenário geral do país. O envio de divisas é uma delas.

O retorno, principalmente quando se repete em várias idas e vindas, é um desses momentos contundentes do transnacionalismo, quando o imigrante se depara com o desafio de operar diretamente numa realidade que, por mais conhecida que tenha sido e apesar dos contatos que continuou mantendo, será percebida com sentimentos de estranhamento. Além dos registros mnêmicos aprisionados às experiências antigas, o estranhamento será também produzido por hábitos, valores e modos de subjetivação absorvidos da cultura do país de destino. Viverá um transnacionalismo espacial e temporal. Espacial porque

1 O estudo de caso que compõe este artigo foi realizada em uma pesquisa de mestrado, com bolsa de estudos concedida pela Coordenadoria de Aperfeiçoamento de Pessoal de Nível Superior (CAPES). Disponível em: <https://repositorio.unesp.br/bitstream/ handle/11449/110679/000779151. pdf?sequence $=1$ \&isAllowed $=y>$.

2 O termo "migração" será utilizado para se referir a deslocamentos de um pais a outro, permanentes ou sazonais, quando não houver a necessidade ou intenção de especificar o país de origem ou de destino. O termo "imigração" será referido à vinda de estrangeiros para um determinado país e o termo "emigração" para situações opostas, ou seja, para designar o movimento de saída do país natal rumo a outro.

3 PARELLA, Sònia, CAVALCANTI, Leonardo. Aplicación de los campos sociales transnacionales en los estudios sobre migraciones. 
colocará em ação padrões de relações sociais e de subjetivação de espaços diferentes, e temporal, porque também se orientará por registros mnêmicos de um tempo que se foi e que terá que atualizar. O passado cristalizado se infiltra repentinamente no presente, criando dissonâncias e contrastes percepto-cognitivos e emocional-afetivos produzindo uma experiência ímpar da trans-temporalidade típica do viajante que é assaltado por uma sensação de estranhamento após um período de ausência do lugar.

Os retornos dos dekasseguis, embora imbricados no seu projeto de imigração, são influenciados por oscilações na economia dos dois países e das políticas de imigração. Por isso alguns permanecem mais tempo do que o planejado inicialmente, outros abreviam a permanência e existem, ainda, aqueles que repetem a experiência várias vezes. Entre os problemas e desafios que surgem na diversidade dessa experiência, se destacam aqueles relacionados aos filhos. É comum se ter crianças acompanhando a saga da família, passando por experiências diversas. Algumas emigram bem novas com os pais ou nascem no Japão e retornam bem mais tarde, já na adolescência, para o Brasil. Nesses casos o retorno dos pais acarreta a emigração dos filhos que se sentem japoneses. Outras emigram com um pouco mais de idade, permanecem pouco tempo no Japão, mal aprendem a língua japonesa e retornam tentando reaver o que tinham deixado para trás e que está gravado vivamente em suas memórias ${ }^{4}$. Em qualquer caso, o retorno será sempre um grande desafio e exigirá da criança ou do adolescente um esforço de re/adaptação.

As experiências migratórias produzem impactos psicológicos consideráveis ${ }^{5}$ que são elaborados de maneira distinta, conforme as singularidades de cada um, inclusive, no que diz respeito à idade, à história e ao ciclo de vida. A experiência da migração difere para adultos, homens e mulheres, casados e solteiros, pais e filhos, crianças, jovens ou idosos.

Crianças e jovens geralmente migram com seus pais ou familiares e pouco participam da decisão de emigrar ou do retorno. Mesmo na companhia de familiares vivem ansiedades de separação e de perdas acompanhadas, usualmente, de sentimentos de insegurança, hostilidade e atitudes de isolamento ${ }^{6}$. Seja quando emigram ou quando retornam terão que conviver com ambientes e espaços psicossociais constituídos fora do espaço familiar. A escola é um desses espaços inevitáveis, onde a criança ou o adolescente terá que realizar a experiência de encontro/confronto com o outro, com o diferente.

4 RESSTEL, Cizina Célia F. Pereira. Desamparo psíquico nos filhos de Dekasseguis no retorno ao Brasil.

5 NAKAGAWA, Kyoko Yanagida. Projeto Kaeru: programa de inclusão dos filhos de trabalhadores brasileiros no Japão às escolas públicas do Estado de São Paulo.

6 YANO, Patrícia. Famílias brasileiras no Japão: migração transnacional, adaptação e estresse aculturativo. 
E tal experiência com um espaço estranho, se faz de maneira repentina e gera, em algum grau, uma situação objetiva de desamparo, sobretudo, quando não há um trabalho de suporte por parte da escola e outras instituições com as quais as crianças e adolescentes passam a conviver ${ }^{7}$.

No contexto migratório, tal desamparo pode ser compreendido como efeito causado pelo contexto de mudança no tecido social. Tal situação de sofrimento gera uma acumulação intensa de excitação no aparelho psíquico que pode buscar o escoamento via somática, psíquica ou social. A experiência de desamparo é mais profunda quanto mais os referentes culturais e psíquicos são questionados ou invalidados com a mudança de país, uma vez que representam os pontos de identificação e pertencimento dos imigrantes a um grupo social.

A constituição do sujeito ocorre num contexto transobjetivo que o sustente, permitindo-lhe se definir como brasileiro, japonês, etc. As marcas da origem primária outorgam ao sujeito uma marca identitária, um traço transobjetivo e uma marca cultural que o insere num código humano, o qual permite que se reconheça como 'sendo de algum lugar'. Tais marcas remetem o sujeito a língua, sabores, odores, dentre outras, que deixam traços pictográficos proprioceptivos, anteriores à palavra, aos quais recorremos para nos serenar e nos reconhecer enquanto um sujeito ${ }^{8}$.

É importante levar em consideração os traços sociais que estruturam o ser humano no mundo que o rodeia, traços que demarcam espaços transobjetivos que definem um contorno no qual o ego se estabelece num conjunto de contenção, valores e normas, fornecendo a inscrição do sujeito e o sentimento de pertencimento a uma determinada cultura. Ou seja, o "vínculo entre o mundo externo e o ego se estabelece sobre a base de um acordo inconsciente, vivido como as raízes que se inserem em uma zona geográfica, social determinada" ${ }^{\prime \prime}$. Isso significa que somos inscritos no mundo a partir de e através dos outros que nos incluem no espaço com sua pluralidade e alteridade, concedendo-nos uma determinada cultura e um espaço transobjetivo que demarcam um lugar comum entre aqueles que compartilham traços e inscrições semelhantes. Tal aspecto constitui-se na trama do laço social que precede o sujeito e o sustenta na filiação e a um pertencimento reconhecido por um grupo.

Desse modo, a língua materna pode ser considerada um traço de origem primária que concede um amparo psíquico baseado nas marcas sociais que lança os sujeitos nesse espaço reconhecido e compartilhado.

\footnotetext{
DANTAS, Sylvia Duarte et alii. Identidade, migrações e suas dimensões psicossociais.

CARIGNATO, Taeco Toma. A construção de uma clínica psicanalítica para migrantes.

WEISSMANN, Lisette. Sujeitos multiculturais? Cidadãos do mundo?, p. 215.
} 


\section{Objetivo}

A pesquisa da qual foi extraído o presente artigo teve como objetivo principal investigar a experiência do retorno ao Brasil, em crianças que passaram a primeira infância no Japão, particularmente no tocante a ansiedades que eclodem no processo de adaptação à cultura brasileira, vivido no ambiente escolar.

\section{Metodologia}

Realizamos, nesta pesquisa, três estudos de casos utilizando uma abordagem clínico-qualitativa, buscando investigar qualidades e significações ${ }^{10}$ da experiência de imigração em crianças e adolescentes, no retorno dos pais ao país natal. A psicanálise foi tomada como referencial teórico principal para a leitura e compreensão de afetos e sentimentos que emergem na experiência dos filhos dos dekasseguis.

Dentre o conjunto dos participantes da pesquisa geral, selecionamos, para os propósitos do presente artigo, o caso de uma menina que doravante aqui denominada pelo codinome de Eiko. Todos os procedimentos éticos estabelecidos Comitê de Ética em Pesquisa da Faculdade de Ciências e Letras de Assis foram seguidos estritamente.

Realizamos entrevistas preliminares com os pais, com o propósito de esclarecer os objetivos da pesquisa e obter o consentimento livre e esclarecido, para a realização da pesquisa com sua filha e para o levantamento de dificuldades em sua adaptação escolar. Com Eiko, além de entrevistas, também recorremos a desenhos projetivos com a finalidade de coleta de dados e não terapêuticos, com o intuito de ampliar os meios de expressão de seus afetos e pensamentos relacionados à sua experiência de contato com a cultura brasileira.

As entrevistas foram gravadas e registradas por meio de anotações e posteriormente transformadas em relato cursivo, no qual se procurou preservar as expressões originais dos participantes. A duração de cada entrevista foi de 1 hora. Foram realizadas vinte e quatro entrevistas com a adolescente Eiko, no período de 19/04/2012 à 02/07/2013. Nessa ocasião, fazia seis meses que chegara ao Brasil.

\section{Apresentação do caso}

Os pais de Eiko, o senhor Ito tem 39 anos e a senhora Natsu de 33 anos de idade são "sansei", ou seja, pertencem à terceira geração de japoneses. O senhor Ito foi para o Japão em 1992, tinha 20 anos de idade e a senhora Natsu em 1997, aos 17 anos e idade. Conheceram-se no Japão e se casaram no Brasil.

10 TURATO, Egberto Ribeiro. Tratado da metodologia da pesquisa clínico-qualitativa: construção teórico-epistemológica, discussão comparada e aplicação nas áreas da saúde e humanas. 
No Japão, residiram em Matsumoto/Província de Nagano, região central do país e trabalharam como operários de fábrica, almoxarifado e hotelaria.

Devido à crise de 2008, deflagrada pelo sistema financeiro norteamericano e que abalou profundamente o Japão, muitos dekasseguis perderam seus empregos. Nesse panorama, o senhor Ito ficou desempregado e a senhora Natsu continuou trabalhando, porém, seu salário não era suficiente para sustentar toda a família. Decidiram, então, retornar ao Brasil, em meados de 2009, sendo que Ito teve a palavra final sobre tal decisão.

Segundo eles, as dificuldades do retorno se iniciaram antes mesmo da chegada ao Brasil. Surgiram grandes preocupações com a vida escolar dos seus filhos, sendo a primeira delas com a diferença dos calendários escolares entre os países.

\section{Caso Eiko}

A adolescente tinha nove anos e nove meses de idade quando a família retornou ao Brasil. Depois que Eiko nasceu, os pais permaneceram por mais seis meses no Japão e retornaram para o Brasil. Passados dois anos, quando estava prestes a completar três anos de idade, a família retornou para o Japão. Segundo os pais, ela diz ser japonesa, alegando que nasceu no Japão.

Eiko frequentou creche e escola japonesas. Havia terminado o terceiro ano do ensino fundamental quando veio para o Brasil, neste último retorno de sua família. Na escola japonesa, teve dificuldades com a escrita denominada "kanji"11, tendo que frequentar aulas de reforço. Mesmo se considerando uma japonesa, era vista como filha de imigrantes brasileiros e não como uma japonesa nata. A comunicação em casa, com os pais, ocorria na língua japonesa, portanto, não teve contato com a língua portuguesa.

Quando Eiko veio para a primeira entrevista tinha 12 anos e meio de idade e fazia três anos que estava no Brasil. Apresentava traços fenotípicos nipônicos além de um comportamento tímido, retraído e passivo. O som de sua voz era baixo, misturado com uma fonética trêmula, entrecortada, como se não pudesse fazer uma ligação entre as palavras faladas com a língua portuguesa. As palavras eram ditas com muitas dificuldades. Portanto, sua forma de se expressar continha traços culturais típicos dos valores da sociedade japonesa, diferente do comportamento habitual de uma criança nascida no Brasil ${ }^{12}$. Porém, era filha de brasileiros nascida no Japão. Quando chegou ao Brasil, se deparou com as diferenças culturais e a dificuldades de adaptação para se reintegrar ao novo e desconhecido país, que ela considerava como sendo seu país de "destino", que ela não escolheu para viver. Com o passar do tempo de realização das entrevistas,

\footnotetext{
${ }^{11}$ Kanji: Forma de caracteres da escrita japonesa.

12 NAKAGAWA, op. cit.
} 
sua voz mostrava-se mais fortalecida, porém, as dificuldades de adaptação continuaram, principalmente com a língua portuguesa e por não conseguir fazer vínculos de amizade.

Em 2013, Eiko frequentava o $8^{\text {o }}$ ano, reprovou o $5^{\text {o }}$ ano, pois havia acabado de chegar ao Brasil, em julho de 2009. Ela ingressou na escola brasileira em agosto de 2009, sem saber o idioma português. Seus pais, durante esse período, contrataram professores particulares para ensiná-la. Também se dispuseram a estudar juntos com a filha. Apresentava muitas dificuldades com a língua portuguesa e sentia-se envergonhada quando arriscava falar alguma coisa, acabava por se isolar, não conseguindo fazer amigos.

\section{Análise e discussão do caso}

A escola é uma caixa de ressonância dos conflitos e desafios enfrentados pelos filhos dos imigrantes. Dois incidentes ocorridos com Eiko na sala de aula demonstram contratempos rotineiros provocados por desencontros de hábitos e simbologias de culturas distintas. Certa vez, recebeu uma advertência, na disciplina de língua portuguesa, por ter se negado, através de movimento com a cabeça que significa "não", a ler verbos, a pedido da professora. Seguramente a professora entendeu tal gesto como uma conduta de indisciplina e não como uma insegurança e temor da criança por não ter domínio da língua. Recebeu outra advertência em matemática por não ter feito a tarefa de casa, gesto esse também entendido pela professora como uma indisciplina. No entanto, justifica esse descumprimento do dever escolar dizendo que para ela era um enorme sofrimento o aprendizado da matemática no Brasil porque os procedimentos de cálculo eram muito diferentes daqueles que tinha aprendido no Japão. "Não sei fazer essa coisa", disse ela, numa das entrevistas. A matemática brasileira, tão incompreensível para ela, passa a ser chamada de "coisa". Afirma: "Aprendi divisão chorando". Embora não tenha sido possível aprofundar nas entrevistas o sentido da divisão, fica a impressão de que essa operação da matemática tinha algo mais a ver com os dramas de separação/ divisão que estava vivendo intensamente.

O sofrimento não se restringe à escola. Em casa, tentava justificar, para sua mãe, suas dificuldades no aprendizado de matemática. Nesses momentos se via sozinha e mal entendida pela sua própria mãe, sentindo uma situação de desamparo emocional.

Pesquisadora (P) Parece-me Eiko que a sua mãe não pode entender que era diferente a forma de divisão do Japão e do Brasil. Eiko(E) Não! Eu vi na apostila do Japão e mostrei para a minha mãe. Ela entendeu. (...) Não vi essa conta. Como posso fazer? O que significa? É menos? É mais? Não perguntava. Pensei: Acho que é uma forma do Brasil. Acho que não é de menos e não mais. (P)Parece-me que se sentiu sozinha. Como se não tivesse ninguém para lhe ajudar. (E) Sim! Teve um formulário e tive que 
escrever, eu não entendia o que era "emprego", só "trabalho". O sétimo ano era muito difícil. ${ }^{13}$

Nesse formulário mencionado, tinha uma pergunta que pedia para assinalar a raça. Comentou que ficou se imaginando nas cores, amarela, branca e negra. Optou por branca. Ela ri e fala que não sabia. Portanto, sente que não pode ser sincera em seu formulário de respostas, faltou com a verdade por não ter conhecimento na língua portuguesa. Hoje, sabe que sua cor, na cultura brasileira, é designada como amarela. Também aqui, em que pese a ausência de mais elementos da narrativa de Eiko, nas entrevistas, é possível conjecturar que o branco, para ela, na resposta ao questionário, significava um não saber sobre si e sobre o mundo associado a uma recusa em se posicionar, em assumir-se como diferente, como uma estranha. Assim, teria preferido diluir-se no branco, numa cor neutra.

O aprendizado da língua portuguesa vem sendo um dos maiores desafios para essas crianças na chegada ao Brasil. Aquelas que estudaram somente em escolas japonesas, acabaram por desenvolver a fala e a escrita no idioma japonês. Nesse caso, os pais escolheram falar a língua japonesa em casa, enquanto estavam no Japão, pensando em facilitar o domínio da língua e a integração de seus filhos.

Quando essas crianças chegam ao Brasil, se deparam com a dificuldade da língua, além das diferenças culturais com as quais passam a se defrontar. Começam a se sentir "estrangeiras" dentro do país de sua nacionalidade e, às vezes, dentro do seu próprio ambiente familiar, caindo em um estado de desamparo psíquico ${ }^{14}$.

(E) Com a palavra em português está um pouquinho difícil. E também não conseguindo ir junto com os meus colegas, eu atrasei um pouquinho. ${ }^{15}$

Ela usa a metáfora dos degraus de uma escada para classificar-se na escola em relação aos demais colegas, dizendo que se encontra nos degraus de baixo e os colegas nos degraus de cima. Sente-se atrasada e inferiorizada em relação aos colegas de classe e isso a incomoda e prejudica suas aproximações e identificações com o ambiente e a cultura escolar com os quais se defronta no Brasil, reacendendo suas lembranças e imagens do período que vivia no Japão.

Apesar de viver no Brasil, seu mundo interno continua japonês, demonstrando que em seus sonhos noturnos, a língua e as paisagens são japonesas e sente-se compreendida, ao contrário do que ocorre na vida diurna. Nutrir a língua japonesa é a forma de manter-se vinculada a uma imago de mãe oriental protetora de compreensiva e de manter vivo o desejo de retorno ao Japão.

\footnotetext{
${ }^{13}$ RESSTEL, op. cit., p. 108.

14 NAKAGAWA, op. cit.

15 Ibidem, p. 109.
} 
O sentimento de desamparo, inferioridade e vergonha impedem ou cerceiam Eiko de falar na sala de aula e se expor perante os outros. Numa das entrevistas, indagada se tirava as dúvidas com a professora, disse que "perguntou pequeno", isto é, que não conseguiu falar na altura suficiente para chamar a atenção da professora e ser ouvida.

(P) Você viveu alguma situação que não sabia que perguntou ao professor e os colegas riram? (E) Eu perguntei pequeno. (P) Você falou baixo? (E) Não ouviu. ${ }^{16}$

No primeiro dia na escola brasileira, viveu uma experiência traumática diante do não reconhecimento dos símbolos que compõem o novo espaço, uma vez que as perdas ocasionadas pela imigração geram rupturas nos elos que ligam o sujeito ao seu lugar de pertencimento. Ela não pode reconhecer as marcas do lugar, uma vez que não compartilha dos aspectos que o compõe. Até os odores são diferentes.

(E) O que eles estão falando? Será que eles não entendem japonês? (P) Como que você se sentiu nesse dia? (E)Nossa! Um pouquinho! É realmente brasileiro? Estão no Japão? Muito assustada! Eles conseguem falar muitas palavras em brasileiro. Lugar é diferente. A professora parece brava. Senti totalmente diferente. (P) Como diferente? (E) Que no Japão e no Brasil é diferente. A escola é muito diferente. Estranhava. Não era escola. Pensava que não era escola. Os professores, amigos e outras pessoas não era japonês. O rosto do japonês percebe que é japonês. O rosto do brasileiro parece italiano,... Eu fiquei um pouquinho, escola ou biblioteca? Passava o tempo e eu entendi que era escola. Que a escola normal do Brasil era assim. ${ }^{17}\left(\right.$...) O cheiro do Japão é um pouquinho de chuva. ${ }^{18}$

Podemos considerar a experiência migratória um trauma psíquico decorrente da irrupção de uma experiência de sofrimento diante da violência ou do terror próprios de algumas situações peculiares e específicas nas quais o sujeito fica exposto ao impacto de mudanças como ocorre na experiência de ruptura resultante da experiência migratória. Tal ruptura remete à perda da terra natal e da língua materna, dos aspectos identificados como reconhecidos e compartilhados com um grupo, gerando uma experiência do estrangeiro, daquele que não ocupa o seu lugar, vem de fora e, portanto, ocupa um lugar de alteridade marcado pela exclusão.

Assim, a nossa atenção foca-se na constituição da língua materna e da palavra, compreendidas como constitutiva tanto do sujeito como de suas relações com o mundo que o cerca. Cada língua tem o seu modo particular de interpretar a atribuir significados ao mundo e às experiências, gerando um

\footnotetext{
${ }_{16}$ RESSTEL, op. cit., p. 116.

17 Ibidem, p. 117.

18 Ibidem, p. 132.
} 
laço identitário entre aqueles que compartilham desse mesmo instrumento simbólico. Afinal, a

língua materna pode ser definida como sendo a dos afetos e prazeres, a que é implícita, secreta, íntima, e que, por mais que se queira, nunca desaparece, deixando marcas que se manifestam através da entonação da voz, do ritmo da fala, dos lapsos e dos vestígios, (...) funcionando de forma completamente inconsciente para o sujeito. ${ }^{19}$

O choque entre as imagens mnêmicas que trazia da cultura japonesa com aquelas percebidas na cultura brasileira tornou-se mais acentuado no ambiente escolar. Além da língua, as imagens também eram outras e contrastantes. Certa vez, disse que os traços físicos dos brasileiros eram bem diferentes dos japoneses, assim como os edifícios. Depara-se com novos objetos, formas de relacionamento, valores, práticas e costumes que lhes soam como estranhos. Às vezes, ficava vagando pelas imagens que via e nada reconhecia, sequer tinha a sensação de que aquele lugar, de fato, era uma escola.

(E) No primeiro dia fiquei perdida. Quando terminou o lanche, foi no banheiro. Eu entrei no banheiro. As amigas foram beber água. Eu estava no banheiro, no primeiro andar. Eu saí do banheiro e não sabia onde estava o bebedouro. Não sabia onde estavam as amigas, mas procurei. Eu estudava no segundo andar. Eu procurei no terceiro andar e também no primeiro. Eu não sabia. Eu abria a porta e via o professor e os alunos. Nossa! Tinha esse amigo nessa sala? Até passei na minha sala. Não conseguia achar a minha sala. (P) E como achou? (E) Eu estava perdida. Uma moça perguntou: O que estava acontecendo? Eu respondi: Perdi. Ela perguntou: O que perdeu? Eu respondi: Eu. A professora estava procurando eu. ${ }^{20}$

Nesse trecho, ela descreve seu estranhamento e a sensação de ter perdido seu 'eu', demonstrando que não pode se sentir pertencente ao lugar.

(E) Aqui é diferente. Assim, ficar um pouquinho com dúvida. Um lugar que nunca vi e nunca fui. (P) Onde você se sente estranha? (E) Mesa é diferente, mesa, piso parece uma pedra, o clima, o ar é diferente, é quente. Tem pessoas falando línguas diferentes. Tem outras pessoas com rosto que não é Japão. (P) Você gosta de vir aqui conversar comigo? (E) Sim. Porque a professora [psicóloga] entende o que eu falo. ${ }^{21}$

Tudo é estranho, desde a mesa ao clima e fisionomia das pessoas. Sua sensação de estranhamento, de si mesma e do outro, se aprofunda nos desencontros e nas não identificações com os objetos e cenários à sua volta.

(E) $\mathrm{Na}$ escola fiquei chateada, no começo com todo mundo fiquei um pouquinho. O rosto, a língua, a altura era diferente, fiquei com medo. (P)

\footnotetext{
${ }^{19}$ KOLTAI, Caterina. Traumas decorrentes dos deslocamentos forçados, p. 134.

20 Ibidem, p. 117.

21 Ibidem, p. 118.
} 
Qual era esse medo? (E) As pessoas do Japão não falam as palavras, ficam magoadas. No Brasil já ouvi tanto as palavras burra e chata... ${ }^{22}$

Não é somente a língua, mas toda a linguagem, todos os signos se tornam estranhos e incompreensíveis, inclusive, a fisionomia e altura das pessoas. A língua materna é um instrumento da articulação entre o individual e o social, por isso, a perda desse elo entre o sujeito e sua terra de origem acarreta um sofrimento que diz respeito ao seu pertencimento e de seus aspectos identitários que o definem como um sujeito. Por isso, além da língua, sente-se incapaz de reconhecer os demais sinais do ambiente ${ }^{23}$.

Apesar de se ver forçada a desenvolver e descobrir uma nova língua fruto de uma mistura entre suas idas e vindas, seu passado e o presente, suas ambiguidades e os lugares experimentados e assim, realizar um trabalho de elaboração do luto pelas perdas vivenciadas, constituindo uma nova possibilidade de identidade que abarque toda essa diversidade de experiências, Eiko acaba permanecendo enrijecida. Não consegue viver espontaneamente e integralmente com seus mundos, sendo impedida de deixar-se penetrar pelos fluxos do novo entorno. Alguns pares da sala de aula tentam se aproximarem dela, mas sem sucesso.

(E) É um pouquinho difícil. A minha aparência na escola é silenciosa e gelada com todo mundo. (P) O que é aparência silenciosa? (E) Não fala muito. Muito baixinho. (P) E aparência gelada? (E) Exemplo: As pessoas falam: Vamos brincar? Eu falo não... (P) Qual é o sentimento que aparece aí? (E) Quero mudar um pouquinho. Ainda está igual quando veio no Brasil, mas o corpo acostumou. Não quer acreditar de verdade. Já acostumou com pessoas do Japão, cultura e língua. O corpo sente mais do que sentimento, não quer fazer mexer. (P) Lá no Japão era diferente? (E) Era bem diferente no Japão. Estou brincando e conversando com os amigos. Estou sozinha no Brasil. Estou junto com os amigos no Japão... (P) Quando você olha e vê que está no Brasil, como que é? (E) Já conversei com a mãe. O meu sentimento e corpo não quer acertar isso. Estou sentindo que estou no Brasil. O sentimento de verdade, não quer acertar. Está muito difícil. ${ }^{24}$

Eiko diz, no fim desse trecho transcrito de sua fala, que seu corpo não quer "acertar". No contexto da fala ela quis dizer que seu corpo e sentimentos não queriam "aceitar" os modos da cultura brasileira. Nessa fala ela explicita a profunda identificação com o Japão e o bloqueio em relação à brasilidade. Não se trata apenas de sentir alguma inadequação, descompasso entre ela os colegas de escola ou falta de traquejo para se inserir em brincadeiras e na cultura infanto-juvenil brasileira. Há um grande bloqueio expresso por uma "aparência silenciosa e gélida".

\footnotetext{
22 Ibidem, p. 262.

${ }^{23}$ KOLTAI, op. cit.

24 Ibidem, p. 123.
} 
É necessário lembrar que Eiko nasceu no Japão, veio com seis meses para o Brasil e havia retornado ao Japão com aproximadamente três anos de idade. Mesmo com referências muito distantes e esvaecidas de sua estadia no Brasil e da origem brasileira de sua família, vez ou outra relembrada por seus pais, mantinha alguma imagem desse país e alimentava a curiosidade de um dia conhecê-lo. Sentiu a iminência dessa segunda viagem como uma mudança que até poderia ser temporária, mas que soava como uma despedida daquele lugar que representava seu "canto no mundo" e que não pretendia abandonar como sua moradia ${ }^{25}$.

(E) Fiquei um pouquinho triste, mas eu também queria vir no Brasil, porque queria conhecer. Estava pensando quando era pequena, ouvi onde que eu fiquei, quando era fica no Brasil (sussurrou as últimas palavras). (...) Não queria sair da escola, porque tinha amigas e amigos, professoras e professores que eu gostava e tinha minhas primas, tias e tios e avós. ${ }^{26}$

A separação do país, da escola, dos amigos e de familiares próximos (tios, primos e avós) que permaneceram no Japão é sentida como perda, despertando um sentimento de luto que se acentua na medida em que se defronta com dificuldades de assimilar e se integrar aos hábitos, costumes e valores da cultura brasileira, principalmente no cotidiano da escola.

Cabe frisar a experiência vivenciada principalmente pela segunda geração de imigrantes que, educada na cultura e no lugar de acolhimento, desenvolve a língua e o sistema de valores desse lugar, e, na experiência de retorno, se vê forçada a integrar presente e passado que não coincidem ${ }^{27}$. Por isso, as questões identitárias chamam tanto a atenção nesses jovens e crianças, que vivem como se tivessem perdido um elo na cadeia geracional e não raramente, respondem ou por uma rejeição radical à sua cultura de origem ou, ao contrário, por um apego exagerado às tradições de sua origem.

(P) E aqui no Brasil, como está? (E) Está um pouco difícil de falar a verdade. O sentido verdade para as pessoas. Tenho um pouco, já me acostumei no Japão. No Brasil têm coisas, costumes diferentes. Não consigo me acostumar muito com os costumes e a cultura. Não consigo ficar muito alegre. (P) Por que está falando que está difícil de dizer a verdade? (E) Minha personalidade tem bastante e igual eu. Fácil de falar e comunicar, mais do que no Brasil. No Brasil a personalidade é diferente das personalidades das pessoas. É difícil falar, não consigo muito..... ${ }^{28}$

Em sua fala acentua que se sente estrangeira no Brasil, não consegue assimilar os costumes nem falar a língua local, enquanto no Japão tinha

\footnotetext{
25 YANO, op. cit.

${ }^{26}$ RESSTEL, op. cit., p. 126.

27 KOLTAI, op. cit.

${ }^{28}$ RESSTEL, op. cit., p. 129.
} 
pessoas como ela. A dificuldade com a língua não é apenas instrumental, mas também de expressar pensamentos e sentimentos de uma maneira que ela, comparando com o modo de se exprimir do japonês, considera uma maneira mais espontânea associada a estados de efusão afetiva. No Brasil, como ela diz, a "personalidade é diferente" e esse é outro complicador para ela falar e se comunicar. No entanto, mostra-se resignada e acredita que com o tempo "vai gostar um pouquinho" do Brasil.

Além disso, vive a batalha para ser bem sucedida no desempenho escolar e na própria vida. Apareceram sentimentos depressivos, de fracasso e de inferioridade associados à percepção de seu baixo rendimento escolar aferido pelas médias das notas obtidas nas avaliações.

(P) Você sente que está lutando sozinha? (E) (...) Um pouco. (...) Contra as provas e os exercícios também. (P) Parece-me que essa luta é difícil. Você sente que está conseguindo? (E) Mais ou menos. Às vezes sou derrotada também. (P) O que é derrotada? (E) Quando tem prova e tirar nota vermelha. Sou derrotada. ${ }^{29}$

A exigência de desempenho e as cobranças que faz para si mesma se tornam mais incisivas e são potencializadas pelas suas dificuldades de comunicação e de adaptação. Mesmo ciente das condições desiguais entre ela e os outros colegas de sala, ainda assim se recrimina por notas baixas.

Ao lado da sensação de fracasso no desempenho escolar, do estranhamento dos hábitos da cultura brasileira e das dificuldades para se integrar aos ambientes, até mesmo no círculo familiar, Eiko preserva, em contraste, sentimentos de profunda identificação e de assimilação da cultura japonesa onde se sentia integrada, segura, confiante e amparada. Refere-se como um local e círculo de relacionamentos no qual se sentia bem, alegre e acolhida.

(E) O Japão é mais, acostumei mais Japão, e consigo ficar, não ficar com vergonha e assim, não ficar sem conversar com colegas, conversa com colegas, então eu gosto de lá. (P) O que é o Brasil? O que você pensa do Brasil? (E) Legal e importante para mim. Mas a língua é diferente do Japão, eu fico um pouquinho com dúvidas e, não consigo falar muito com colega e fico um pouquinho com judiada com comigo mesmo. (P) Como é ficar judiada com você mesmo? (E) Porque não consigo, não consigo ficar, falar o que eu quero e de conversar. Tenho vergonha de falar errado e fico quietinha, não consigo. ${ }^{30}$

A maneira como vive as diferenças desperta sentimentos de inadequação, fracasso, vergonha, paralisia, insegurança, incerteza, estranhamento de si e

\footnotetext{
${ }^{29}$ Ibidem, p. 130.

${ }^{30}$ Ibidem, p. 132.
} 
do ambiente, tudo isso envolvido por uma sensação de desamparo na qual demanda ajuda para operar na nova situação, mas não encontra ou não se sente respaldada seja pelos professores, pelos colegas de escola ou até mesmo por familiares. Tal situação parece evidenciar uma dificuldade em elaborar o sentimento da perda, a qual gera uma sensação de abandono e a impossibilidade psíquica de elaboração busca refúgio na nostalgia do lugar perdido, como se fosse possível retornar ao paraíso perdido.

\section{Síntese conclusiva}

O mundo atual exige certa flexibilidade nos referentes identitários e maior disponibilidade para a convivência com movimentações e mudanças frequentes que ocorrem no entorno do sujeito, sejam produzidas pelos seus próprios deslocamentos de um lugar a outro ou por transformações nos cenários locais. Diferentemente de outras épocas nas quais a vida era mais sedentária, plantada em lugares fixos e estáveis, hoje ela está sujeita a mobilidades geográficas e psicossociais mais frequentes que podem transpor fronteiras nacionais e de identidades culturais bem estabelecidas. Contudo, as condições para a mobilidade e práticas transnacionais ainda são precárias e construídas a duras penas pelos próprios migrantes. No Brasil, as políticas públicas de assistência preocupadas em minimizar os sofrimentos e dificuldades que se colocam na experiência de migração são precárias e, no geral, oferecidas por organizações voluntárias ${ }^{31}$. Como se pode observar nesse caso, a escola não está preparada para receber um filho de dekassegui retornado, e, ao menos na localidade para a qual a família retornou, não existe serviço de apoio aos migrantes. Tais negligências deixam migrantes e seus filhos expostos às vicissitudes de contingências econômicas, sociais, políticas e culturais e à mercê da própria sorte ou dos próprios recursos para enfrentarem as adversidades. Foi o que ocorreu com Eiko e sua família, afetados pela crise econômica internacional que se abateu no Japão e pela situação do Brasil nesse cenário. Esse cenário caracteriza o que poderíamos chamar de desamparo social e político e que potencializa e acentua a experiência de desamparo psicológico.

O sentimento de desamparo psicológico é inevitável, porém, poderia ser acompanhado em sua elaboração e transformado em uma experiência positiva e enriquecedora, porque a experiência do imigrante é uma experiência radical de aventura pelo desconhecido, imprevisível e de busca e encontro/confronto com o estranho, com o diferente e com o outro. O caso de Eiko é muito transparente quanto a experiências de temor, estranhamento, embate com as diferenças, bloqueios e fracasso que despotencializam aquilo que ela tem de mais precioso: um capital cultural, social e psicológico adquirido no tempo que viveu no Japão.

${ }^{31}$ NAKAGAWA, op. cit. 
Sua experiência migratória coincide com outra transição importante em seu processo de desenvolvimento psicológico. Com seus 13 anos de idade, junto com seu transito por espacialidades tão diferentes entre os países, está iniciando uma transição no tempo da infância à adolescência, cujos conflitos não são menores.

A idade pesa consideravelmente no tipo de experiência da imigração, de tal forma que as crianças de menor idade assimilam com mais facilidade a nova e contrastante realidade do país de destino do emigrante ${ }^{32}$.

Além da idade, a duração, o tipo de experiência com a escola japonesa terá reverberações na adaptação à escola brasileira. O problema não se resume ao fato de terem imigrado com uma ou outra idade ou de terem estudado em escolas japonesas ou brasileiras, mas sim o de não existirem práticas educacionais e culturais que valorizem o capital transnacional e que até estimulem a preservação e desenvolvimento de línguas e culturas estrangeiras ao lado das nacionais.

Emigrar é se defrontar com o estranho e o desconhecido, mais ainda, é se reconstruir subjetivamente, é produzir "formas diferentes de pensar, sentir, perceber e falar, [exigindo] transformações pessoais profundas que beiram a uma despersonalização ou a um desmanche da identidade pessoal, difícil de ser suportada" ${ }^{\prime 3}$. Trata-se de viver profundamente uma experiência de travessia, de transito por pontes que ligam territórios existenciais distintos, temporalidades e espacialidades diferentes. A ponte como metáfora da condição subjetiva dos dekasseguis, no entanto, não significa uma experiência de ligação simplesmente de modos de ser distintos, de unificação de aspectos comuns que possam ser compartilhados e que poderia ser compreendido como uma experiência de intersubjetividade. $\mathrm{O}$ ir e vir, o estar aqui e lá, simultaneamente, enquanto uma contração tempo/espaço, possível no plano da experiência, produz subjetivações construídas no movimento, na passagem de um lugar/tempo a outro.

A objetividade do transnacionalismo, entendida como relações sociais que se prolongam por dois países ou que produzem efeitos de simultaneidade em espaços distintos, é acompanhada de processamentos psicológicos que caracterizam o que poderíamos chamar de transubjetivações ${ }^{34}$, isto é, produções psicológicas (afetos, sentimentos, pensamentos, cognições, condutas, identificações) híbridas, que se realizam no trânsito entre um lugar e outro. Contudo, o transnacionalismo no plano econômico não traz maiores dificuldades para os imigrantes. O dinheiro transita com facilidade no mundo

\footnotetext{
${ }^{32}$ GRINBERG, Leon, GRINBERG, Rebeca. Psicoanalisis de la migracion y del exilio.

33 JUSTO, José Sterza. A chegada dos imigrantes japoneses e a partida dos dekasseguis: dois lados da mesma viagem, p. 100.

${ }^{34}$ JAROSLAVSKY, Ezequiel Alberto. Indicadores de violencia en el vínculo de pareja. De la transmisión transubjetiva a la intersubjetiva.
} 
todo, sendo amplamente conversível e podendo gerar efeitos em qualquer país. O mesmo não acontece com as produções subjetivas, com as identidades pessoais e culturais, com bagagens de vida construídas em diferentes lugares.

Eiko não teve a oportunidade de habitar um espaço transnacional constituído pela hibridização de duas culturas. Não pôde conviver, simultaneamente, com línguas, conhecimentos, hábitos, costumes, valores e outras produções das sociedades brasileira e japonesa com a intensidade que Ihe garantisse situar-se numa ou noutra dessas culturas sem sentir um efeito profundo de estranhamento e desamparo ${ }^{35}$. Vive dificuldades e desafios de uma condição concreta de vida que exige dela que se posicione num ou noutro lugar, dificultando que transporte e utilize sua bagagem subjetiva e que realize hibridizações culturais, sociais e psicológicas. A transubjetividade, nesse caso, refere-se, a uma transição do sujeito no tempo e no espaço no qual ele se constitui e produz sua existência em movimento, saltando dos lugares cristalizados, produzindo hibridismos, criando estranhamentos nas familiaridades. A experiência psíquica da transubjetivação, ao lado da experiência sociológica e cultural do transnacionalismo talvez seja o aspecto principal e inovador da experiência da imigração tal como ela se realiza na atualidade.

\section{Bibliografia}

CARIGNATO, Taeco Toma. A construção de uma clínica psicanalítica para migrantes. REMHU, Revista Interdisciplinar da Mobilidade Humana, Brasília, Ano XXI, n. 40, jan./jun. 2013, p. 107-129.

DANTAS, Sylvia Duarte et alii. Identidade, migrações e suas dimensões psicossociais. REMHU, Revista Interdisciplinar da Mobilidade Humana, Brasília, Ano XVIII, n. 34, jan/jun 2010, p. 45-60.

GRINBERG, Leon; GRINBERG, Rebeca. Psicoanalisis de la migracion y del exilio. Madrid: Alianza, 1984.

JAROSLAVSKY, Ezequiel Alberto. Indicadores de violencia en el vínculo de pareja. De la transmisión transubjetiva a la intersubjetiva. Psicoanaslisis \& Intersubjetividad: família, pareja, grupos e instituciones, n. 03, jun. 2008, p. 1-14. Disponível em: $<$ http://www.intersubjetividad.com.ar/website/articulo.asp?id=192\&idd=3>. Acesso em: 23.05.2017.

JUSTO, José Sterza. A chegada dos imigrantes japoneses e a partida dos dekasseguis: Dois lados da mesma viagem. In HASHIMOTO, Francisco; TANNO, Janete L.; OKAMOTO, Monica S. (orgs.). Cem Anos da Imigração Japonesa: história, memória e arte. São Paulo: Editora UNESP, 2008, p. 99-123.

KOLTAI, Caterina. Traumas decorrentes dos deslocamentos forçados. Revista Diversitas, mar/set. 2013, p. 131-137.

${ }^{35}$ NAKAGAWA, op. cit. 
NAKAGAWA, Kyoko Yanagida. Projeto Kaeru: programa de inclusão dos filhos de trabalhadores brasileiros no Japão às escolas públicas do Estado de São Paulo. São Paulo: Edição do autor, 2010.

PARELLA, Sònia; CAVALCANTI, Leonardo. Aplicación de los campos sociales transnacionales en los estudios sobre migraciones. In SOLÉ, Carlota; PARELLA, Sònia; CAVALCANTI, Leonardo (orgs.). Nuevos retos del transnacionalismo en el estudio de las migraciones. Barcelona: Grafo, S.A 2008, p. 216-243. Disponível em: <http://extranjeros.empleo.gob.es/es/ObservatorioPermanentelnmigracion/ Publicaciones/fichas/archivos/Nuevos_retos_del_transnacionalismo_en_el_ estudio_de_las_migraciones.pdf $>$. Acesso em: 23.05.2017.

RESSTEL, Cizina Célia Fernandes Pereira. Desamparo psíquico nos filhos de Dekasseguis no retorno ao Brasil. Dissertação (mestrado) - Universidade Estadual Paulista, Faculdade de Ciências e Letras de Assis, 2014. Disponível em: < http:// hdl.handle.net/11449/110679>. Acesso em: 23.05.2017.

TURATO, Egberto Ribeiro. Tratado da metodologia da pesquisa clínico-qualitativa: construção teórico-epistemológica, discussão comparada e aplicação nas áreas da saúde e humanas. Rio de Janeiro: Vozes, 2003.

YANO, Luciane Patrícia. Famílias brasileiras no Japão: migração transnacional, adaptação e estresse aculturativo. Porto Alegre: Poá Comunicação, 2013.

WEISSMANN, Lisette. Sujeitos multiculturais? Cidadãos do mundo? In GOMES, Isabel Cristina; FERNANDES, Maria Inês Assumpção; LEVISKY, Ruth Blay (orgs.). Diálogos psicanalíticos sobre família e casal. São Paulo: Zagodoni, 2012.

Recebido para publicação em 30.05.2017

Aceito para publicação em 08.08.2017

Received for publication in May 30 Accepted for publication in August 08 ${ }^{\text {th }}, 2017$

ISSN impresso 1980-8585

ISSN eletrônico 2237-9843

http://dx.doi.org/10.1590/1980-85852503880005012 